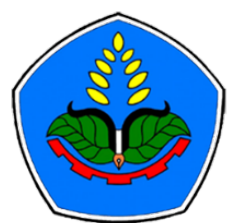

AGROPROSS

National Conference Proceedings of Agriculture
Proceedings:

Peningkatan Produktivitas Pertanian Era Society 5.0 Pasca Pandemi

Tempat : Politeknik Negeri Jember

Tanggal : 22 Juli 2021

Publisher :

Agropross, National Conference Proceedings of Agriculture

ISBN : 978-623-94036-6-9

DOI : 10.25047 /agropross.2021.212

\title{
Pengaruh Jenis Tanaman Tumpangsari pada Budidaya Jeruk Ramah Lingkungan Terhadap Kualitas Buah Jeruk Keprok Terigas
}

\author{
Author(s): Titistyas Gusti Aji*, Sutopo, Umi Nurul Taflikhah, Sri Wahyuni, Endang \\ Sutriana
}

Balai Penelitian Tanaman Jeruk dan Buah Subtropika, Jalan Raya Tlekung No. 1, Junrejo, Kota Batu, Jawa Timur

* Corresponding author: titistyasgusti@pertanian.go.id

\section{ABSTRACT}

Public awareness of a healthy lifestyle has led to an increase in the demand for organic products, including citrus fruits. Although it has not been implemented on a wide scale, environmentally friendly citrus cultivation has been carried out at the farmer level, including in East Java, Bali, Bengkulu, and West Java. In the area between the rows of citrus, several annual crops are planted which aim to suppress weed growth, as an organic fertilizer, and can be a source of income. This experiment aimed to study the effect of planting annual crops on environmentally friendly citrus cultivation on the internal and external quality of the fruit. Fruit analysis was conducted at the Ecophysiology Laboratory, Indonesian Citrus and Subtropical Fruit Research Institute, Batu, in July 2020. The experiment was arranged using a randomized block design, with the factors tested were types of intercropping plants. There were 4 levels tested, namely soybeans, green beans, peanuts, and sweet potatoes, each with 10 replications. The results showed that planting sweet potatoes as an intercropping plant was able to produce citrus fruits with higher fruit weight, edible part weight, and juice volume than green beans and peanuts, but not significantly different from soybeans. Intercropping had no significant effect on peel and seed weight, fruit diameter, total dissolved solids, TSS:TA ratio, and vitamin C content. The use of sweet potatoes or soybeans as intercropping plants in environmentally friendly citrus cultivation can be applied to produce high quality citrus fruits.
\end{abstract}

\section{Keywords:}

Citrus reticulata, environmentally friendly; external quality; intercropping; internal quality.

\section{Kata Kunci: ABSTRAK}

Citrus reticulata; kualitas eksternal; kualitas internal; ramah lingkungan; tumpangsari
Kesadaran masyarakat akan gaya hidup sehat menyebabkan peningkatan permintaan produk organik, termasuk buah jeruk. Meskipun belum diterapkan pada skala luas, budidaya jeruk yang ramah lingkungan telah dilakukan di tingkat petani, di antaranya di Jawa Timur, Bali, Bengkulu, dan Jawa Barat. Pada lahan sela di antara barisan jeruk, ditanam beberapa tanaman semusim yang bertujuan untuk menekan pertumbuhan gulma, sebagai bahan pupuk organik, serta dapat menjadi sumber pendapatan. Percobaan ini bertujuan untuk mempelajari pengaruh penanaman tanaman semusim pada budidaya jeruk ramah lingkungan terhadap kualitas internal dan eksternal buah. Analisis buah dilakukan di Laboratorium Ekofisiologi, Balai Penelitian Tanaman Jeruk dan Buah Subtropika, Kota Batu pada bulan Juli 2020. Percobaan disusun menggunakan Rancangan Acak Kelompok, dengan faktor yang diujikan adalah jenis tanaman tumpangsari. Terdapat 4 taraf yang diujikan, yaitu kacang kedelai, kacang hijau, kacang tanah, dan ubi jalar, masing-masing dengan 10 ulangan. Hasil yang diperoleh menunjukkan bahwa penanaman ubi jalar sebagai tanaman tumpangsari mampu menghasilkan buah jeruk dengan bobot buah, bobot daging buah, dan volume jus yang lebih tinggi dibandingkan kacang hijau dan kacang tanah, namun tidak berbeda nyata dengan kacang kedelai. Penanaman tanaman tumpangsari tidak berpengaruh signifikan terhadap bobot kulit dan biji buah, diameter buah, total padatan terlarut, rasio TPT:TAT, dan kandungan vitamin C. Penggunaan ubi jalar atau kacang kedelai sebagai tanaman tumpangsari pada budidaya jeruk ramah lingkungan dapat diterapkan untuk menghasilkan buah jeruk yang berkualitas. 


\section{PENDAHULUAN}

Penggunaan agroinput kimia sintetis merupakan hal yang telah dilakukan selama bertahun-tahun, sejak Revolusi Hijau digalakkan di Indonesia pada tahun 1970-an. Bahan kimia sintetis baik pupuk, pestisida, hormon tumbuh, serta bahan kimia lainnya memiliki manfaat untuk mendukung pertumbuhan dan hasil tanaman. Meskipun demikian, aplikasi bahan kimia sintetis yang tidak tepat dalam jangka panjang dapat berbahaya bagi kesehatan manusia, di antaranya keracunan, gangguan pernafasan, hingga terganggunya sistem dan kerja organ tubuh (Agustin \& Muhartono, 2018; Agustina, 2014; Pamungkas, 2016; Yuantari, 2011; Yuantari et al., 2015). Selain itu, penggunaan bahan kimia sintetis yang berlebihan juga mengancam lingkungan, termasuk penurunan kualitas air, tanah, dan udara, peningkatan resistensi dan resurjensi organisme pengganggu tanaman, terganggunya keseimbangan biodiversitas, serta tercemarnya hasil pertanian (Las et al., 2006). Oleh karena itu, diperlukan strategi untuk menghasilkan produk pertanian berkualitas yang proses produksinya ramah lingkungan dan berkelanjutan, serta aman bagi kesehatan manusia.

Konsep pertanian ramah lingkungan berkelanjutan merujuk pada praktik budidaya yang meningkatkan kualitas lingkungan dan sumberdaya pertanian dalam jangka panjang, dapat diakses dan diterapkan oleh petani, mengarah pada peningkatan produktivitas dan kualitas produk pertanian, layak secara ekonomi, serta meningkatkan kualitas hidup petani dan masyarakat secara keseluruhan (Abubakar \& Attanda, 2013; Adnyana, 2001; Efendi, 2016; Irawan, 2013; Pretty, 2008). Beberapa sistem pertanian yang termasuk dalam konsep di atas adalah low input sustainable agriculture (LISA), low external input sustainable agriculture (LEISA), pertanian terpadu, pertanian presisi, pertanian konservasi, pertanian cerdas-iklim, permakultur, agroforestri, dan pertanian organik.

Kesadaran masyarakat akan gaya hidup sehat menyebabkan peningkatan permintaan produk organik (Khorniawati, 2014; Muljaningsih, 2011), termasuk buah jeruk. Meskipun belum diterapkan pada skala luas, budidaya jeruk yang ramah lingkungan telah dilakukan di tingkat petani, di antaranya di Jawa Timur, Bali, Bengkulu, Lampung, dan Jawa Barat. Beberapa teknik budidaya ramah lingkungan yang diterapkan yaitu penggunaan pupuk dan pestisida organik maupun hayati, pengendalian hama dan penyakit terpadu, pemanfaatan bahan organik yang ada di sekitar kebun, serta tumpangsari (Bunada et al., 2016; Mufidah, Budiyati, et al., 2020; Mufidah, Widyaningsih, et al., 2020; Rugayah et al., 2020). Teknik di atas bertujuan untuk memperbaiki kesuburan tanah, menekan serangan organisme pengganggu tanaman, meningkatkan biodiversitas, serta meningkatkan kesehatan, pertumbuhan dan hasil tanaman. Selain manfaat tersebut, penerapan tumpangsari secara khusus dapat menyediakan makanan dan tempat berlindung bagi serangga bermanfaat, baik polinator, parasitoid, maupun predator, serta menekan pertumbuhan gulma. Biomassa tanaman tumpangsari dapat menjadi bahan pupuk organik, sedangkan hasil tanaman tumpangsari dapat menjadi sumber pemasukan lain bagi petani (Bunada et al., 2016; Mufidah et al., 2018; Mufidah, Budiyati, et al., 2020; Padmaningrum \& Widiyanti, 2003; Suryadi et al., 2017). Tanaman tumpangsari yang banyak ditanam bersama jeruk adalah padi, tanaman sayuran, dan leguminosa. Penelitian ini bertujuan untuk mengetahui pengaruh jenis tanaman tumpangsari pada budidaya jeruk ramah lingkungan terhadap kualitas eksternal dan internal buah jeruk keprok Terigas. 


\section{METODOLOGI}

Percobaan dilakukan di Instalasi Penelitian dan Pengkajian Teknologi Pertanian (IP2TP) Tlekung, Balitjestro, Kota Batu, yang berada pada ketinggian 950 mdpl. Tanaman yang digunakan adalah jeruk keprok Terigas berumur 5 tahun dengan jarak tanam $4 \mathrm{~m} \times 3 \mathrm{~m}$. Percobaan disusun menggunakan Rancangan Acak Kelompok, dengan faktor yang diujikan adalah jenis tanaman tumpangsari. Terdapat 4 taraf yang diujikan, yaitu kacang kedelai, kacang hijau, kacang tanah, dan ubi jalar. Tanaman tumpangsari ditanam pada bulan Januari 2020 di petak antara barisan jeruk. Analisis kualitas buah dilakukan di Laboratorium Ekofisiologi, Balai Penelitian Tanaman Jeruk dan Buah Subtropika, Kota Batu pada bulan Juli 2020. Buah jeruk yang telah masak fisiologis diambil secara acak dari 10 tanaman sampel dari masingmasing perlakuan. Parameter yang diamati meliputi kualitas eksternal, yaitu bobot buah, bobot bagian dapat dimakan, bobot kulit dan biji, serta ukuran buah. Kualitas internal yang diamati meliputi total padatan terlarut (TPT), total asam tertitrasi (TAT), rasio TPT:TAT, kandungan jus, serta kandungan vitamin C. Data yang diperoleh dianalisis menggunakan uji $\mathrm{F}$. Apabila hasil uji $\mathrm{F}$ menunjukkan bahwa perlakuan berpengaruh signifikan, maka dilanjutkan dengan uji BNT dengan taraf kepercayaan $95 \%$.

\section{HASIL DAN PEMBAHASAN}

Penanaman tanaman semusim menghasilkan pengaruh yang signifikan terhadap beberapa kualitas eksternal dan internal buah jeruk keprok Terigas. Penanaman ubi jalar sebagai tanaman tumpangsari mampu meningkatkan bobot buah, bobot daging buah, dan volume jus yang lebih tinggi dibandingkan kacang hijau dan kacang tanah, namun tidak berbeda nyata dengan kacang kedelai. Penanaman tanaman tumpangsari tidak berpengaruh signifikan terhadap bobot kulit dan biji buah, diameter buah, total padatan terlarut, rasio TPT:TAT, dan kandungan vitamin $\mathrm{C}$.

\section{Kualitas eksternal}

Ubi jalar sebagai tanaman tumpangsari mampu menghasilkan bobot buah jeruk keprok Terigas tertinggi yaitu $86,65 \mathrm{~g}$, namun tidak berbeda nyata dengan kacang kedelai. Hasil yang serupa juga diperoleh pada parameter bobot daging buah. Penggunaan ubi jalar sebagai tanaman tumpangsari menghasilkan bobot daging buah tertinggi, yaitu $61,37 \mathrm{~g}$, namun tidak berbeda dengan kacang kedelai. Teknik tumpangsari dengan tanaman semusim tidak berpengaruh signifikan pada bobot kulit dan biji jeruk keprok Terigas, yaitu 24,14 g (Tabel 1).

Tabel 1. Bobot bagian buah jeruk keprok Terigas organik yang dipengaruhi beberapa tanaman tumpangsari

\begin{tabular}{|l|c|c|c|}
\hline $\begin{array}{c}\text { Tanaman } \\
\text { tumpangsari }\end{array}$ & $\begin{array}{c}\text { Bobot } \\
\text { buah } \\
(\mathrm{g})\end{array}$ & $\begin{array}{c}\text { Bobot } \\
\text { kulit } \\
\text { dan biji } \\
(\mathrm{g})\end{array}$ & $\begin{array}{c}\text { Bobot } \\
\text { daging } \\
\text { buah }(\mathrm{g})\end{array}$ \\
\hline Kacang kedelai & $84,46 \mathrm{ab}$ & $26,64 \mathrm{a}$ & $57,81 \mathrm{ab}$ \\
\hline Kacang hijau & $74,61 \mathrm{~b}$ & $23,26 \mathrm{a}$ & $51,35 \mathrm{~b}$ \\
\hline Kacang tanah & $73,71 \mathrm{~b}$ & $22,60 \mathrm{a}$ & $51,11 \mathrm{~b}$ \\
\hline Ubi jalar & $86,65 \mathrm{a}$ & $24,04 \mathrm{a}$ & $61,37 \mathrm{a}$ \\
\hline
\end{tabular}

Keterangan: angka yang diikuti huruf yang sama pada kolom yang sama menunjukkan tidak berbeda nyata berdasarkan uji BNT pada taraf kepercayaan $95 \%$.

Tumpangsari tidak memberikan pengaruh signifikan terhadap diameter buah, yaitu 5,18 mm. Penggunaan kedelai sebagai tanaman sela menghasilkan tinggi buah yang lebih tinggi dibandingkan kacang hijau, namun tidak berbeda dengan kacang tanah dan ubi jalar (Tabel 2). 
Tabel 2. Ukuran buah jeruk keprok Terigas organik yang dipengaruhi beberapa tanaman tumpangsari

\begin{tabular}{|l|c|c|}
\hline $\begin{array}{c}\text { Tanaman } \\
\text { tumpangsari }\end{array}$ & $\begin{array}{c}\text { Diameter } \\
\text { buah }(\mathrm{mm})\end{array}$ & $\begin{array}{c}\text { Tinggi } \\
\text { buah } \\
(\mathrm{mm})\end{array}$ \\
\hline Kacang kedelai & $5,27 \mathrm{a}$ & $4,90 \mathrm{a}$ \\
\hline Kacang hijau & $5,08 \mathrm{a}$ & $4,56 \mathrm{~b}$ \\
\hline Kacang tanah & $5,08 \mathrm{a}$ & $4,61 \mathrm{ab}$ \\
\hline Ubi jalar & $5,29 \mathrm{a}$ & $4,74 \mathrm{ab}$ \\
\hline
\end{tabular}

Keterangan: angka yang diikuti huruf yang sama pada kolom yang sama menunjukkan tidak berbeda nyata berdasarkan uji BNT pada taraf kepercayaan $95 \%$.

Ubi jalar sebagai tanaman tumpangsari dilaporkan dapat menjaga kelembaban tanah melalui peningkatan laju infiltrasi dan menekan limpasan permukaan (Nedunchezhiyan et al., 2010). Efek menjaga kelembaban tanah oleh legum juga dilaporkan oleh Shirgure (2012) pada sistem tumpangsari jeruk baik dengan kacang kedelai, kacang tanah, maupun lentil hitam (Vigna mungo). Ketersediaan air merupakan faktor penting bagi pertumbuhan dan perkembangan buah. Hal ini diduga menjadi penyebab bobot buah dan bobot daging buah yang lebih tinggi pada perlakuan ubi jalar dibandingkan perlakuan lainnya.

Legum merupakan tanaman yang umum ditanam dengan sistem tumpangsari. Tanaman ini mampu mengikat $\mathrm{N}_{2}$ udara dan mengubahnya menjadi bentuk nitrogen yang tersedia bagi tanaman bila bersimbiosis dengan bakteri tertentu (Armiadi, 2009). Tumpangsari menggunakan tanaman legum secara umum mampu meningkatkan kesuburan tanah melalui fiksasi nitrogen dan meningkatkan konservasi tanah melalui penutupan tanah (cover crops) (Ananthi et al., 2017). Ghosh \& Pal (2010) melaporkan bahwa konsentrasi nitrogen tanah meningkat pada sistem tumpangsari jeruk manis dengan legum. Selain itu, hasil penelitian Zhou et al. (2006) menunjukkan bahwa tumpangsari kedelai dan jeruk meningkatkan mobilitas unsur fosfor pada profil tanah, dan fosfor yang berada di lapisan tanah yang lebih dalam bergerak lebih cepat ke lapisan atas tanah. Pada percobaan ini, kedelai menghasilkan bobot buah, bobot daging buah, dan tinggi buah yang tidak berbeda nyata dengan ubi jalar. Hal ini diduga karena penanaman kedelai menyediakan unsur $\mathrm{N}$ dan $\mathrm{P}$ yang bermanfaat bagi pertumbuhan dan perkembangan buah.

\section{Kualitas internal}

Perlakuan tumpangsari tidak berpengaruh terhadap total padatan terlarut dan rasio TPT:TAT. Total padatan terlarut buah jeruk keprok Terigas berada pada rentang $12,20-12,97^{\circ}$ Brix, sedang rasio TPT:TAT berkisar antara 7,57 - 7,98. Penggunaan ubi jalar sebagai tanaman tumpangsari menghasilkan buah dengan kandungan total asam tertitrasi terendah, yaitu $1,54 \%$, namun tidak berbeda nyata dengan kacang kedelai (Tabel 3).

Tabel 3. TPT, TAT, dan rasio TPT:TAT jeruk keprok Terigas organik yang dipengaruhi beberapa tanaman tumpangsari

\begin{tabular}{|l|c|c|c|}
\hline \multicolumn{1}{|c|}{$\begin{array}{c}\text { Tanaman } \\
\text { tumpangsari }\end{array}$} & $\begin{array}{c}\text { Total } \\
\text { padatan } \\
\text { terlarut } \\
\left({ }^{\circ} \text { Brix }\right)\end{array}$ & $\begin{array}{c}\text { Total } \\
\text { asam } \\
\text { tertitrasi } \\
(\%)\end{array}$ & $\begin{array}{c}\text { Rasio } \\
\text { TPT:TAT }\end{array}$ \\
\hline $\begin{array}{l}\text { Kacang } \\
\text { kedelai }\end{array}$ & $12,34 \mathrm{a}$ & $1,60 \mathrm{ab}$ & $7,81 \mathrm{a}$ \\
\hline Kacang hijau & $12,84 \mathrm{a}$ & $1,70 \mathrm{a}$ & $7,57 \mathrm{a}$ \\
\hline Kacang tanah & $12,97 \mathrm{a}$ & $1,69 \mathrm{a}$ & $7,71 \mathrm{a}$ \\
\hline Ubi jalar & $12,20 \mathrm{a}$ & $1,54 \mathrm{~b}$ & $7,98 \mathrm{a}$ \\
\hline
\end{tabular}

Keterangan: angka yang diikuti huruf yang sama pada kolom yang sama menunjukkan tidak berbeda nyata berdasarkan uji BNT pada taraf kepercayaan $95 \%$.

Penggunaan ubi jalar sebagai tanaman tumpangsari menghasilkan volume jus yang lebih tinggi dibandingkan kacang tanah, namun tidak terbeda nyata dengan kacang kedelai dan kacang hijau. Perlakuan tumpangsari tidak berpengaruh nyata terhadap kandungan vitamin $\mathrm{C}$ buah 
jeruk keprok Terigas, yaitu sebesar 28,48 $\mathrm{mg} / 100 \mathrm{~g}$ jus jeruk (Tabel 4).

Tabel 4. Kadar jus dan kandungan vitamin $\mathrm{C}$ jeruk keprok Terigas organik yang dipengaruhi beberapa tanaman tumpangsari

\begin{tabular}{|l|c|c|}
\hline $\begin{array}{c}\text { Tanaman } \\
\text { tumpangsari }\end{array}$ & $\begin{array}{c}\text { Volume jus } \\
(\mathrm{ml})\end{array}$ & $\begin{array}{c}\text { Vitamin } \\
\mathrm{C} \\
(\mathrm{mg} / 100 \\
\mathrm{g} \text { jus })\end{array}$ \\
\hline Kacang kedelai & $43,30 \mathrm{ab}$ & $28,12 \mathrm{a}$ \\
\hline Kacang hijau & $41,80 \mathrm{ab}$ & $30,00 \mathrm{a}$ \\
\hline Kacang tanah & $38,05 \mathrm{~b}$ & $28,16 \mathrm{a}$ \\
\hline Ubi jalar & $45,80 \mathrm{a}$ & $27,63 \mathrm{a}$ \\
\hline
\end{tabular}

Keterangan: angka yang diikuti huruf yang sama pada kolom yang sama menunjukkan tidak berbeda nyata berdasarkan uji BNT pada taraf kepercayaan $95 \%$.

Padatan terlarut, asam tertitrasi, dan rasio keduanya berkorelasi dengan rasa manis dan asam buah (Ikegaya et al., 2019; Jayasena \& Cameron, 2008; Vangdal, 1985). Rasio TPT:TAT juga digunakan sebagai indikator kematangan buah jeruk (Gupta et al., 2021; Kashyap et al., 2020; Lado et al., 2014). Pada percobaan ini, tumpangsari dengan ubi jalar atau kacang kedelai menghasilkan buah dengan asam tertitrasi yang relatif rendah dengan padatan terlarut yang tidak berbeda dengan perlakuan lainnya. Hal ini menunjukkan bahwa penggunaan ubi jalar atau kacang kedelai cenderung menghasilkan buah dengan rasa yang lebih manis meskipun nilai rasio TPT:TAT tidak berbeda signifikan di antara perlakuan yang diterapkan.

Tumpangsari jeruk keprok Terigas baik dengan ubi jalar, kacang kedelai, maupun kacang hijau menghasilkan volume jus yang relatif tinggi, dengan kandungan vitamin $\mathrm{C}$ yang tidak berbeda nyata dengan perlakuan kacang tanah. Hal ini menunjukkan bahwa buah jeruk keprok yang ditanam secara tumpangsari baik dengan ubi jalar, kacang kedelai, maupun kacang hijau berpotensi memiliki kandungan vitamin $\mathrm{C}$ yang lebih banyak dibandingkan tumpangsari dengan kacang tanah.

\section{KESIMPULAN}

Penanaman ubi jalar sebagai tanaman tumpangsari mampu menghasilkan buah jeruk dengan bobot buah, bobot daging buah, dan volume jus yang lebih tinggi dibandingkan kacang hijau dan kacang tanah, namun tidak berbeda nyata dengan kacang kedelai. Penanaman tanaman tumpangsari tidak berpengaruh signifikan terhadap bobot kulit dan biji buah, diameter buah, total padatan terlarut, rasio TPT:TAT, dan kandungan vitamin $\mathrm{C}$. Penggunaan ubi jalar atau kacang kedelai sebagai tanaman tumpangsari pada sistem budidaya jeruk ramah lingkungan dapat meningkatkan kualitas buah jeruk keprok Terigas.

\section{SUMBER DANA PENELITIAN}

Penelitian ini dilaksanakan dengan menggunakan anggaran DIPA Balai Penelitian Tanaman Jeruk dan Buah Subtropika tahun 2020.

\section{DAFTAR PUSTAKA}

Abubakar, M. S., \& Attanda, M. L. (2013). The concept of sustainable agriculture: Challenges and prospects. IOP Conference Series: Materials Science and Engineering, 53(1), 012001.

https://doi.org/10.1088/1757$899 \mathrm{X} / 53 / 1 / 012001$

Adnyana, M. O. (2001). Pengembangan sistem usaha pertanian berkelanjutan. Forum Penelitian Agro Ekonomi, 19(2), 38-49. https://doi.org/10.21082/fae.v19n2.2 001.38-49

Agustin, R., \& Muhartono. (2018). Dampak penggunaan pestisida organoklorin terhadap risiko kanker payudara. Journal Agromedicine, $5(1), 433-437$.

Agustina, T. (2014). Kontaminasi logam 
berat pada makanan dan dampaknya pada kesehatan. Teknobuga, 1(1), 5365.

https://doi.org/10.1529/jtbb.v1i1.640 5

Ananthi, T., Amanullah, M. M., Rahman, A., \& Al-Tawaha, M. S. (2017). A review on maize-legume intercropping for enhancing the productivity and soil fertility for sustainable agriculture in India. Advances in Environmental Biology, 11(5), 49-63.

Armiadi. (2009). Penambatan nitrogen secara biologis pada tanaman leguminosa. Wartazoa, 19(1), 23-30.

Bunada, I. W., Kesumadewi, A. A. I., \& Atmaja, I. W. D. (2016). Beberapa sifat biologi tanah kebun jeruk siam (Citrus nobilis Tan) pada sistem monokultur dan tumpangsari dengan beberapa tanaman sayuran di Desa Sekaan Kecamatan Kintamani. Agrotrop: Journal on Agriculture Science, 6(2), 180-190.

Efendi, E. (2016). Implementasi sistem pertanian berkelanjutan dalam mendukung produksi pertanian. Jurnal Warta, 47.

Ghosh, S. N., \& Pal, P. P. (2010). Effect of inter-cropping on plant and soil of Mosambi sweet orange orchard under rainfed conditions. Indian Journal of Horticulture, 67(2), 185-190.

Gupta, A. K., Pathak, U., Tongbram, T., Medhi, M., Terdwongworakul, A., Magwaza, L. S., Mditshwa, A., Chen, T., \& Mishra, P. (2021). Emerging approaches to determine maturity of citrus fruit. Critical Reviews in Food Science and Nutrition, O(0), 1-22. https://doi.org/10.1080/10408398.20 21.1883547

Ikegaya, A., Toyoizumi, T., Ohba, S., Nakajima, T., Kawata, T., Ito, S., \& Arai, E. (2019). Effects of distribution of sugars and organic acids on the taste of strawberries. Food Science \&
Nutrition, 7, 2419-2426. https://doi.org/10.1002/fsn3.1109

Irawan. (2013). Pertanian ramah lingkungan: indikator dan cara pengukuran aspek sosial - ekonomi. Prosiding Seminar Nasional Pertanian Ramah Lingkungan, 659674.

Jayasena, V., \& Cameron, I. (2008). ${ }^{\circ}$ Brix/acid ratio as a predictor of consumer acceptability of Crimson seedless table grapes. Journal of Food Quality, 31(6), 736-750. https://doi.org/10.1111/j.17454557.2008.00231.x

Kashyap, K., Kashyap, D., Nitin, M., Ramchiary, N., \& Banu, S. (2020). Characterizing the nutrient composition, physiological maturity, and effect of cold storage in Khasi mandarin (Citrus reticulata Blanco). International Journal of Fruit Science, 20(3), 521-540. https://doi.org/10.1080/15538362.20 19.1666334

Khorniawati, M. (2014). Produk pertanian organik di Indonesia: Tinjauan atas preferensi konsumen Indonesia terhadap produk pertanian organik lokal. Jurnal Studi Manajemen, 8(2), 171-182.

Lado, J., Rodrigo, M. J., \& Zacarías, L. (2014). Maturity indicators and citrus fruit quality. Stewart Postharvest Review, 2(2), 1-6.

Las, I., Subagyono, K., \& Setiyanto, A. P. (2006). Isu dan pengelolaan lingkungan dalam revitalisasi pertanian. Jurnal Penelitian Dan Pengembangan Pertanian, 25(3), 173-193.

Mufidah, L., Budiyati, E., \& Sutopo. (2020). Pemanfaatan lahan sela pada budidaya jeruk sistem tanam rapat di Banyuwangi. Agritech: Jurnal Fakultas Pertanian Universitas Muhammadiyah Purwokerto, 22(1), $1-11$. 
https://doi.org/10.30595/agritech.v22 i1.3903

Mufidah, L., Wicaksono, R. C., \& Endarto, O. (2018). Analisis biaya manfaat penanggulangan burik kusam dengan mulsa dan tanaman tumpangsari pada jeruk keprok. In M. R. Suhartanto, S. I. Aisyah, E. R. Palupi, \& A. Nindita (Eds.), Prosiding Seminar Nasional Perhimpunan Hortikultura Indonesia 2017 (pp. 283-286). IPB Press.

Mufidah, L., Widyaningsih, S., \& Budiyati, E. (2020). Conversion of citrus farming to organic in Dau, Malang, East Java: An improvement discourse. A review. IOP Conference Series: Earth and Environmental Science, $\quad 456(1), \quad 012025$. https://doi.org/10.1088/17551315/456/1/012025

Muljaningsih, S. (2011). Preferensi konsumen dan produsen produk organik di Indonesia. WACANA, Jurnal Sosial Dan Humaniora, 14(4), $1-5$.

Nedunchezhiyan, M., Rajasekhara Rao, K., Laxminarayana, K., \& Satapathy, B. S. (2010). Effect of strip cropping involving sweet potato (Ipomoea batatas L.) on soil moisture conservation, weevil infestation and crop productivity. Journal of Root Crops, 36(1), 53-58.

Padmaningrum, D., \& Widiyanti, E. (2003). Analisis konsekuensi inovasi tumpangsari jeruk dan padi sawah di Kecamatan Ngombol Kabupaten Purworejo. Agritext, 14, 10-16.

Pamungkas, O. S. (2016). Bahaya paparan pestisida terhadap kesehatan manusia. Bioedukasi, 14(1), 27-31.

Pretty, J. (2008). Agricultural sustainability: Concepts, principles and evidence. Philosophical Transactions of the Royal Society B: Biological Sciences, 363(1491), 447465.

https://doi.org/10.1098/rstb.2007.216
3

Rugayah, Karyanto, A., \& Sanjaya, P. (2020). Sinergi budidaya buah dan sayuran berkelanjutan dalam era perubahan iklim di kelompok tani Bina Usaha Pekon Giham Sukamaju Kecamatan Sekincau Lampung Barat. Sinergi, 1, 95-105.

Shirgure, P. S. (2012). Effect of different intercropping systems on soil moisture conservation, fruit yield and quality of Nagpur mandarin (Citrus reticulata) in central India. Scientific Journal of Agricultural, 1(7), 168176.

Suryadi, D., Megawati, A., Susilo, B., Dalimartha, L. N., Wiguna, E. C., Koentjoro, M. P., \& Prasetiyo, E. N. (2017). Model manajemen terpadu pertanian hortikultura organik pada lahan sempit. Proceeding Biology Education Conference, 14(1), 118125.

Vangdal, E. (1985). Quality criteria for fruit for fresh consumption. Acta Agriculturae Scandinavica, 35(1), 41-47.

https://doi.org/10.1080/00015128509 435757

Yuantari, M. G. C. (2011). Dampak pestisida organoklorin terhadap kesehatan manusia dan lingkungan serta penanggulangannya. Prosiding Seminar Nasional Peran Kesehatan Masyarakat Dalam Pencapaian MDG'S Di Indonesia, 187-199.

Yuantari, M. G. C., Widianarko, B., \& Sunoko, H. R. (2015). Analisis risiko pajanan pestisida terhadap kesehatan petani. Jurnal Kesehatan Masyarakat, 10(2), 239-245.

Zhou, W. J., Wang, K. R., Zhang, Y. Z., Yin, L. C., \& Li, H. S. (2006). Phosphorus transfer and distribution in a soybean-citrus intercropping system. Pedosphere, 16(4), 435-443. https://doi.org/10.1016/s10020160(06)60073-8 